\title{
Moderator band connections: an unusual route in retrograde chronic total occlusion procedure: moderator band connections as options to right coronary artery chronic total occlusion
}

\author{
Marcelo H. Ribeiro ${ }^{1,2}$, Luis A. P. Dallan², Expedito E. Ribeiro da Silva ${ }^{2}$, Carlos M. Campos ${ }^{1,2}$, Marouane \\ Boukhris $^{3}$, Alfredo R. Galassi ${ }^{3}$, Daniel Weilenmann ${ }^{4}$, João Antônio Brum da Silveira ${ }^{5}$, Satoru Sumitsuji ${ }^{6}$ \\ IInterventional Cardiology Department, SOS CARDIO Hospital, Florianopolis, SC, 88030-000, Brazil. \\ ${ }^{2}$ Interventional Cardiology Department, Heart Institute (InCor) - University of Sao Paulo Medical School, Sao Paulo, SP, 05403- \\ 900 , Brazil. \\ ${ }^{3}$ Interventional Cardiology Department, University of Catania, Catania, 95124, Italy. \\ ${ }^{4}$ Interventional Cardiology Department, Saint Gallen Hospital, Saint Gallen, CH-9007, Switzerland. \\ ${ }^{5}$ Interventional Cardiology Department, Centro Hospitalar do Porto, Hospital de Santo Antônio, Porto, 4099-001, Portugal. \\ ${ }^{6}$ Interventional Cardiology Department, Osaka University, Osaka, 565-0871, Japan.
}

Correspondence to: Luis Augusto Palma Dallan. InCor - Heart Institute - HCFMUSP - University of Sao Paulo Medical School Department of Interventional Cardiology Av Dr. Eneas de Carvalho Aguiar, 44 - Pinheiros - Sao Paulo, SP, 05403-900 Brazil. E-mail: luisdallan@yahoo.com

\begin{abstract}
How to cite this article: Ribeiro MH, Dallan LAP, da Silva EER, Campos CM, Boukhris M, Galassi AR, Weilenmann D, da Silveira $J A B$, Sumitsuji S. Moderator band connections: an unusual route in retrograde chronic total occlusion procedure: moderator band connections as options to right coronary artery chronic total occlusion. Vessel Plus 2019;3:21.
\end{abstract} http://dx.doi.org/10.20517/2574-1209.2018.66

Received: 30 Sep 2018 First Decision: 4 Mar 2019 Revised: 10 Apr 2019 Accepted: 22 May 2019 Published: 13 Jun 2019

Science Editor: Alfredo R. Galassi Copy Editor: Cai-Hong Wang Production Editor: Jing Yu

\begin{abstract}
We describe a right coronary artery (RCA) chronic total occlusion (CTO) percutaneous coronary intervention ( $\mathrm{PCI}$ ) procedure in a very high risk patient, in whom a complex $\mathrm{PCl}$ with the support of Impella CP device plus Rotablator rotational atherectomy was performed 6 months ago to revascularize a very calcified left anterior descendent. This was an unusual approach because it was performed through a very rare connection by retrograde technique. It was performed through a third distal septal branch connecting with the moderator band artery. Reverse controlled antegrade and retrograde tracking technique was then successfully performed. After RCA CTO PCI, there was an improvement in the patient symptoms and quality of life. This case highlights the important role of this unusual and rare source of collateral circulation in RCA CTO.
\end{abstract}


Keywords: Chronic total occlusion complex, percutaneous coronary intervention, right coronary artery, retrograde approach, moderator band

\section{INTRODUCTION}

The use of the retrograde approach ${ }^{[1-9]}$ has dramatically increased in the last years, not only throug the septal collaterals and saphenous venous graft ${ }^{[10]}$, but also via epicardial connections ${ }^{[11]}$ to the chronic total occlusion (CTO) lesion.

We report the case of a right coronary artery (RCA) CTO recanalized using the retrograde approach through the contralateral channels of a third septal artery connecting with the moderator band artery [Figure 1] that was connected with the right ventricular branch of the RCA.

\section{CASE REPORT}

A 64 year-old male, with hypertension, dyslipidemia, left ventricle dysfunction with $35 \%$ ejection fraction, and known coronary artery disease. A previous percutaneous coronary intervention (PCI) was performed 6 months before revascularizing an extremely calcified left anterior descendent artery with rotational atherectomy and Impella CP mechanical circulatory support. The patient remained symptomatic due to RCA CTO [Figure 2] with $24 \%$ ischemic burden involving the inferior wall in myocardial scintigraphy. Therefore, PCI of RCA CTO was indicated.

We started the procedure through double femoral access, trying to perform the anterograde approach. We tried to reach the intimal plaque and then the distal vessel, first using AL-1 guide catheter 7F in the RCA, Turnpike spiral microcatheter (Teleflex), Fielder FC guidewire (Asahi Intec.) and Conquest Pro 12 (Asahi Intec.), however without success. After $15 \mathrm{~min}$, we decided to switch retrograde approach, using EBU 4.0 7F guide catheter in left coronary. We used a Turnpike spiral microcatheter (Teleflex) and a Whisper Light Support (Abbott) guidewire to access the third septal, where we could navigate into a connection through the moderator band artery into the right posterior atrioventricular branch. Then, we used the Turnpike Spiral microcatheter to replace the previous guidewire for a new Sion (Asahi Intec.) guidewire due to the fragility of this channel. After accessing the RCA [Figure 3], the reverse controlled antegrade and retrograde tracking technique [Figure 4] was performed and the retrograde guidewire was externalized [RG3 (Asahi Intec.)]. As we reached the RCA in the middle part of the vessel, we used a double lumen catheter TwinPass (Teleflex) to introduce a Fielder FC guidewire anterogradely into the distal RCA, and then PCI with 3 DES Xience Alpine (Abbott) was performed with a good result [Figure 5].

\section{DISCUSSION}

The retrograde approach has dramatically increased as an alternative to recanalize complex CTO in case of anterograde failure. Data from the ERCTO registry showed that retrograde approach was only used in $15 \%$ of the CTO procedures ${ }^{[12]}$. The septal collaterals are the safest and easiest to track to achieve retrograde access, but in our case we showed an unusual route of the septal channel that was connected probably with the moderator band artery ${ }^{[13]}$. Sadek et al ${ }^{[14]}$ described this forgotten access, showing that first, the moderator band is a muscle column that courses inferiorly from the right portion of the interventricular septum to the base of the anterior papillary muscle of the right ventricle. Second, the source of the moderator band artery lies in the first three septal arteries, most often in the second one; in our case we used the less common third one. Finally, this artery makes connections with various branches of the RCA, hence representing a real source of collateral circulation to RCA CTO as we practically demonstrated through this case. 


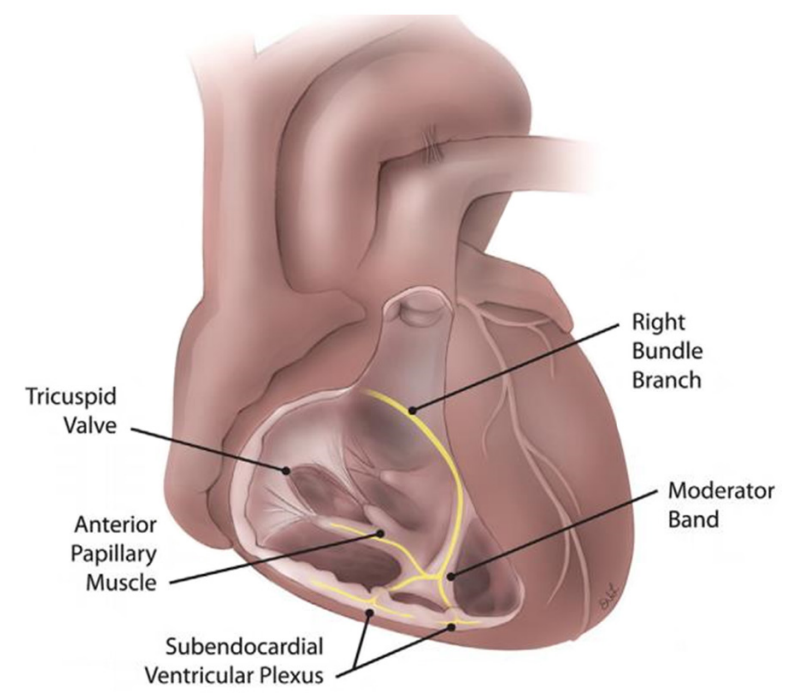

Figure 1. Anatomy of the moderator band artery, crossing from the septum to the free wall of the right ventricle and supporting the anterior papillary muscle of the tricuspid valve

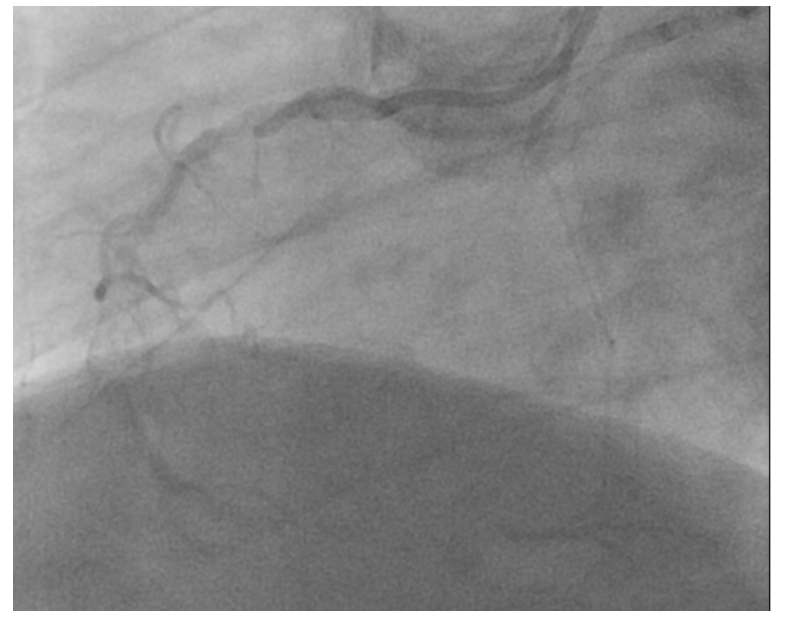

Figure 2. Very calcified and long CTO segment in RCA. RCA: right coronary artery

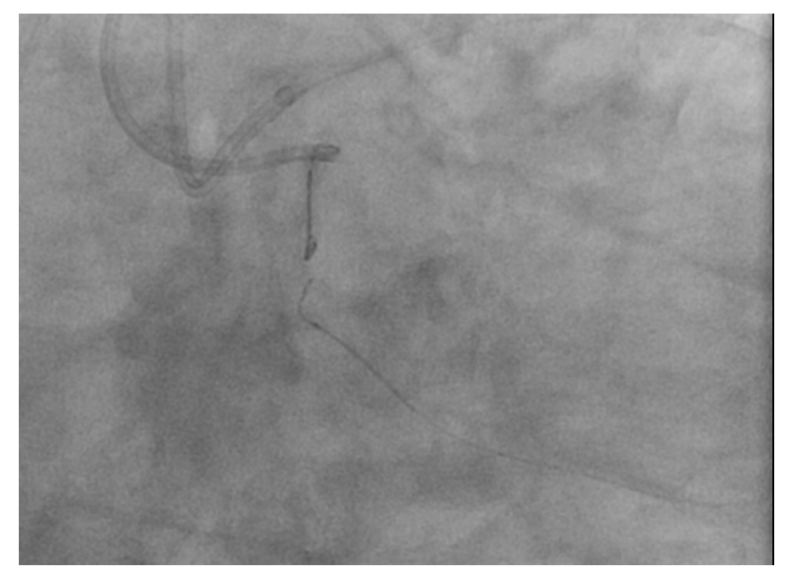

Figure 3. With a Whisper LS we crossed through the moderator band artery to a Right Ventricular Ramus reaching the RCA. RCA: right coronary artery 


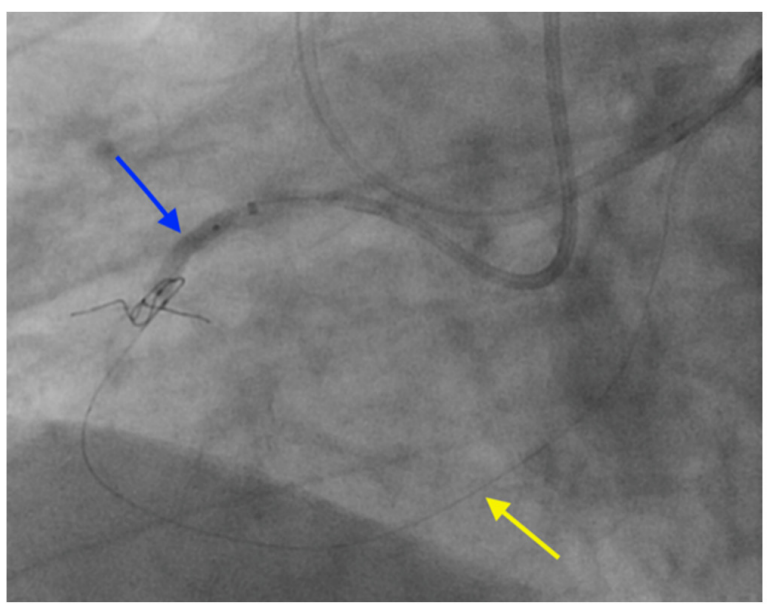

Figure 4. The yellow arrow shows the route through the moderator band and the blue arrow shows the reverse cart in the proximal RCA. RCA: right coronary artery

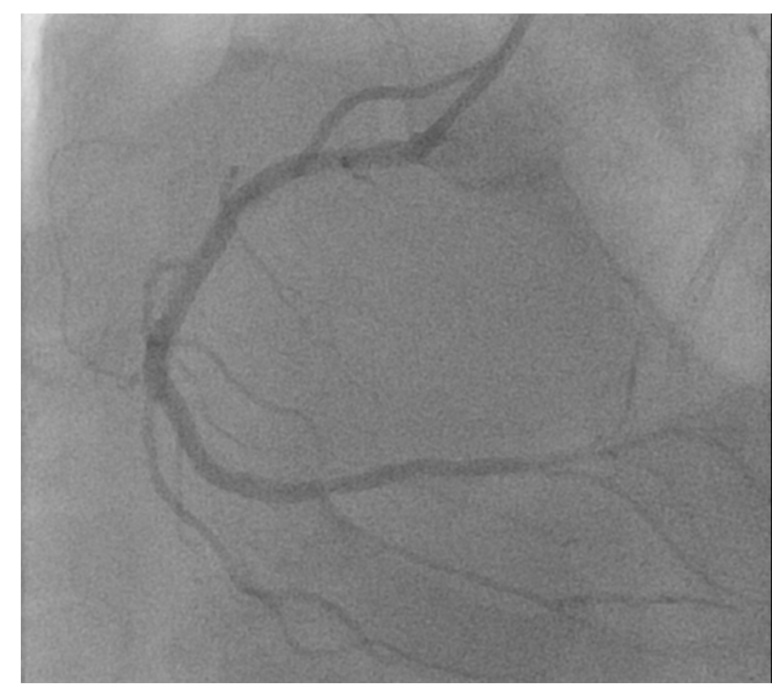

Figure 5. Pervious RCA with 3 Xience Alpine stents $3.0 \mathrm{~mm} \times 38 \mathrm{~mm}$. RCA: right coronary artery

To the best of our knowledge, this is the first case report of a retrograde approach using the moderator band artery as source of collaterals to open a RCA CTO.

In conclusion, the retrograde route described above could be useful for CTO RCA cases after antegrade failure and when standard approach of using the septal collaterals to connect with the posterior descendent artery is not available.

\section{DECLARATIONS}

\section{Authors' contributions}

Contributed substantially in data interpretation and writing: Dallan LAP, Ribeiro MH, Boukhris M Contributed substantially reviewing the manuscript for important intellectual content: da Silveira JAB, Campos CM, Galassi AR

Contributed substantially in the analysis and interpretation of data: Weilenmann D, da Silveira JAB Contributed in data collection, interpretation and manuscript review for important intellectual content: Sumitsuji S 


\section{Availability of data and materials}

Not applicable.

\section{Financial support and sponsorship}

None.

\section{Conflicts of interest}

All authors declared that there are no conflicts of interests.

\section{Ethical approval and consent to participate}

Not applicable.

\section{Consent for publication}

Not applicable.

\section{Copyright}

(C) The Author(s) 2019.

\section{REFERENCES}

1. Sukiennik A, Kasprzak M, Mazurek W, Niezgoda P, Bednarczyk Ł, et al. High-risk percutaneous coronary intervention with Impella CP hemodynamic support. A case series and method presentation. Postepy Kardiol Interwencyjnej 2017;13:67-71.

2. Dudek D, Rakowski T, Sukiennik A, Hawranek M, Dziewierz A, et al. Circulatory support with Impella CP device during high-risk percutaneous coronary interventions: initial experience in Poland. Postepy Kardiol Interwencyjnej 2016;12:254-7.

3. Redondo Dieguez A, Cid Alvarez AB, Trillo Nouche R, López Otero D, Ocaranza Sánchez R, et al. Impella CP-Assisted High-risk Coronary Percutaneous Intervention: First Experience in Spain. Rev Esp Cardiol (Engl Ed) 2017;70:403-5. (in English, Spanish)

4. Kim MH, Kim HJ, Kim NN, Yoon HS, Ahn SH, et al. A rotational ablation tool for calcified atherosclerotic plaque removal. Biomed Microdevices. 2011;13:963-71.

5. Marchant E, Martinez A, Fajuri A, Guarda E, Valenzuela E, et al. Rotational atherectomy (Rotablator) for percutaneous transluminal coronary angioplasty. Rev Med Chil 1997;125:1474-82.

6. Dash D. Retrograde coronary chronic total occlusion intervention. Curr Cardiol Rev2015;11:291-8.

7. Galassi AR, Sianos G, Werner GS, Escaned J, Tomasello SD, et al. Retrograde recanalization of chronic total occlusions in Europe: procedural, in-hospital, and long-term outcomes from the multicenter ERCTO registry. J Am Coll Cardiol 2015;65:2388-400.

8. Reig J, Alberti N, Petit M. Arterial vascularization of the human moderator band: an analysis of this structure's role as a collateral circulation route. Clin Anat 2000;13:244-50.

9. Applegate RJ. Retrograde percutaneous coronary intervention for chronic total occlusion: going backward to go forward. J Am Coll Cardiol 2015;65:2401-3.

10. Nguyen-Trong PK, Alaswad K, Karmpaliotis D, Lombardi W, Grantham JA, et al. Use of saphenous vein bypass grafts for retrograde recanalization of coronary chronic total occlusions: insights from a multicenter registry. J Invasive Cardiol 2016;28:218-24.

11. Benincasa S, Azzalini L, Carlino M, Bellini B, Giannini F, et al. Outcomes of the retrograde approach through epicardial versus nonepicardial collaterals in chronic total occlusion percutaneous coronary intervention. Cardiovasc Revasc Med 2017;18:393-8.

12. Galassi AR, Tomasello SD, Reifart N, Werner GS, Sianos G, et al. In-hospital outcomes of percutaneous coronary intervention in patients with chronic total occlusion: insights from the ERCTO (European Registry of Chronic Total Occlusion) registry. EuroIntervention 2011;7:472-9.

13. Barlis P, Di Mario C. Retrograde approach to recanalising coronary chronic total occlusions immediately following a failed conventional attempt. Int J Cardiol 2009;133:e14-7.

14. Sadek MM, Benhayon D, Sureddi R, Chik W, Santangeli P, et al. Idiopathic ventricular arrhythmias originating from the moderator band: Electrocardiographic characteristics and treatment by catheter ablation. Heart rhythm. 2015;12:67-75. 